\title{
Portal hypertension in chronic hepatitis: relationship to morphological changes
}

\author{
D J van Leeuwen, S C Howe, P J Scheuer, Sheila Sherlock
}

\begin{abstract}
Various anatomical factors were examined which might provide passive resistance to portal venous flow and so cause portal hypertension. Methods included the measurement of portal pressure (WHVPG) in cirrhotic and non-cirrhotic patients, morphological assessment by semiquantitative grading of severity of disease, calculation of hepatocyte size indices, and assessment of volume density of hepatocytes, sinusoids, Disse's space and Disse's space collagen by electron microscopy. The wedged hepatic venous pressure gradient increased with progression of disease and portal hypertension was present before histologically detectable cirrhosis had developed. With increasing progression of disease towards cirrhosis, the relationship between individual and aggregated features and the WHVPG diminished and lost statistical significance. Hepatocyte size increased with progression of histological changes and correlated significantly with increase of WHVPG, both in nonalcoholic and alcoholic patients. Disse's space collagen was increased significantly in nonalcoholic chronic active hepatitis compared with patients with near-normal liver. No significant decrease of sinusoidal space was found. Multiple factors rather than any single feature influence the development of portal hypertension.
\end{abstract}

Recent studies, largely on animals and patients with alcoholic liver disease, have suggested that anatomical factors other than compression of the liver vasculature by regenerative nodules' might play a role in the development of portal hypertension. Such flow obstructing factors could include the contraction of myofibroblasts, ${ }^{23} \mathrm{en}$ largement of hepatocytes and the collagenisation of Disse's space. ${ }^{+7}$

Intrahepatic portal hypertension has traditionally been associated with cirrhosis. Portal hypertension, however, has been found in precirrhotic alcoholic and non-alcoholic liver disease..$^{8-11}$

The purpose of the present study was to determine whether individual anatomical characteristics could be identified as contributing to the development of portal hypertension, by causing passive resistance to flow in patients with chronic hepatitis before cirrhosis had fully developed.

\section{Methods}

\section{PATIENTS}

Clinical and biochemical data were obtained from 49 patients, admitted for liver biopsy. These patients were consecutively selected on the basis of (i) abnormal liver function tests, (ii) need for further diagnostic investigations, (iii) usually moderate or no alcohol intake. The biopsy specimens of a further 11 patients (six with chronic active hepatitis and five with alcoholic cirrhosis were added for the study of a limited number of questions (vide infra).

\section{PRESSURE RECORDING}

From all 49 patients informed consent was obtained to assess portal venous pressure by

TABLE I Morphological assessment of liver biopsies in 37 patients and the wedged hepatic venous pressure gradients

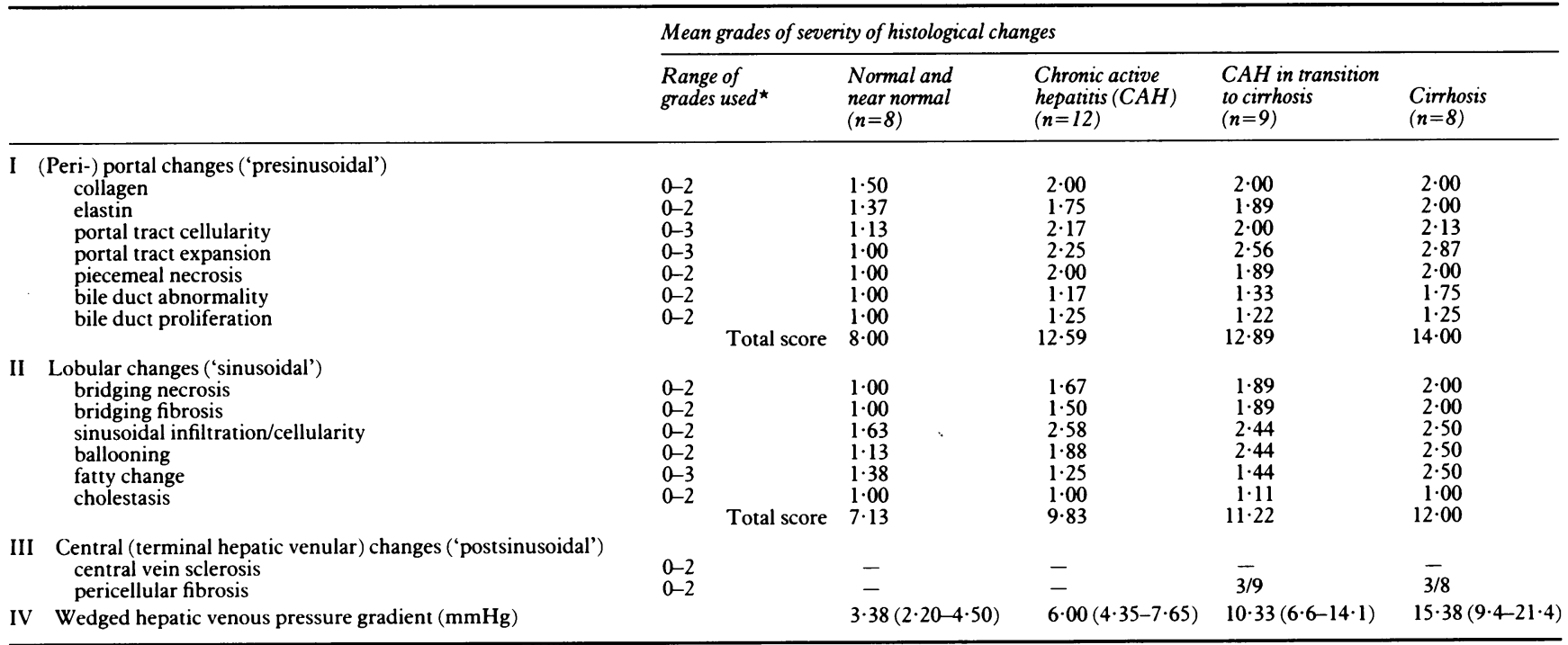

${ }^{\star}$ Grades of severity: 0 =absent, 1 = present, normal; 2 =present, abnormal, increased; 3 =very strong (certain features only). 
measuring the wedged hepatic venous pressure gradient (WHVP-FHVP), using a balloon catheter. ${ }^{12}$ The technical aspects, pressure patterns and venographic appearances are reported elsewhere. ${ }^{13}$

HISTOLOGICAL ASSESSMENT

The formalin fixed, paraffin embedded liver biopsies were stained with haematoxylin and eosin (H \& E), for reticulin (Gordon and Sweets) and by at least one more connective tissue method (orcein, elastin-van Gieson or chromotrope-aniline blue). Based on light microscopy the patients were grouped into five categories: near normal (eight), chronic active hepatitis (12), chronic active hepatitis in transition to cirrhosis (nine), established cirrhosis (eight) and miscellaneous (12). Special attention was paid to whether cirrhosis had developed; patients whose biopsies showed nodularity and fibrosis but which were not considered to have fully developed cirrhosis were classified as having chronic hepatitis 'in transition to cirrhosis'. Some of these patients might have had cirrhosis, however, which was not clearly seen in the biopsy sections.

\section{SEMIQUANTITATIVE ASSESSMENT OF LIVER BIOPSIES}

The histological features listed in Table I were semiquantitatively graded on a $0-3$ scale. For evaluation, they were grouped into changes at presinusoidal, sinusoidal and postsinusoidal level because these three groups (assumed obstruction levels) are well established in clinical concepts of portal hypertension. ${ }^{14}$ is For that reason miscellaneous cases were not further analysed. The initial observations were made by one observer (DJvL), and reproducibility was checked by a second observer (PJS). Differences in the grading between investigators were slight, never exceeding one grade and not exceeding $15 \%$ of the biopsy specimens.

\section{MORPHOMETRIC ASSESSMENT}

In 34 patients (Table II), a hepatocyte surface index was calculated. This hepatocyte surface index represents the surface area/ the sizes of the hepatocytes as described in detail elsewhere. ${ }^{15}$ The total number of cross sections in at least five different midzonal areas, both in the horizontal and vertical direction, was counted by light microscopy with integrating eyepieces at a magnification level of 320x (Zeiss graticule and microscope). The smaller the cells, the higher the number of cross sections, for example, the index is inversely related to the cell size. This work was performed in a limited number of patients because our interest was focused upon a comparison between normals, chronic active hepatitis and cirrhotics. Miscellaneous cases were left out, but the biopsy specimens of six patients with chronic active hepatitis (nonalcoholic) and five alcoholic cirrhotics were included to increase the number of specimens available for this part of the study. Their specimens became available during the study period and they were processed in the same way as the other specimens.

In 34 patients, specimens for electron microscopy were obtained using a standardised technique (fixation within $30 \mathrm{~s}$ in $3 \%$ glutaraldehyde and storage at $4^{\circ} \mathrm{C}$ ). Resin embedding was performed using a standardised automated technique in a Histomat (LKB). Toluidine blue stained semithin $1 \mu \mathrm{m}$ sections were used to select midzonal areas. Cutting of all specimens was performed by one technician. A rough check of the specimens was performed by comparing paraffin ( $H$ \& E), semithin and ultrathin sections, an effort being made to select comparable areas consisting mainly of parenchymal cells. Further sections were then cut as necessary. It was hoped in this way to obtain either midzonal areas, or homogenous parts of nodules in cirrhotic patients. Photographs were taken with a Philips TEM 201 electron microscope at the lowest possible magnification, equivalent to $470 x$ on $35 \mathrm{~mm}$ negative film, and printed on paper to a size of $19 \times 19 \mathrm{~cm}$. At this final magnification (2551x, approximately 12-15 cells per photograph) Disse's space, the sinusoidal space and the collagen in Disse's space (using the periodicity in structure of collagens I and III) could be assessed. Point counting was applied for measuring volume densities with a multi-purpose grid. ${ }^{16}$ The volume densities of the total hepatocyte mass (Vh), the collagen in Disse's space (Vdsc), the sinusoidal space (Vs) and Disse's space (Vds) were calculated. At least 10 pictures were analysed for each assessment. (The volume density of the various items reflect their proportional volume part of the tissue as a whole.)

\section{STATISTICAL ANALYSIS}

Statistical analysis was performed using one way analysis of variance, Student's $t$ test and Spearman's rank test as appropriate. Further calculations including assessment of linear regression coefficients were calculated using the MINITAB program (Pennsylvania State University).

\section{Results}

The results of the assessment of the features in the periportal, lobular and central areas in 47 patients are summarised in Table I. In general, increase in score paralleled increase in severity of disease. Typical pericellular fibrosis was only rarely seen and in the group we studied central vein sclerosis was not observed.

CORRELATION OF SEMIQUANTITATIVE LIGHT MICROSCOPICAL CHANGES AND WEDGED PRESSURE GRADIENTS

The correlation coefficients $(r)$ between scores for different histological areas and the wedged hepatic venous pressure gradients (WHVPFHVP) are summarised in Table III. This Table shows the correlations between the sums of the scores of periportal and lobular scores, respectively and the results when the coefficients are calculated with exclusion of the group of cirrhotic patients. The Table includes the results of the sums of scores in periportal and lobular 
TABLE II Hepatocyte size indices in 34 patients. The indices relate inversely to the hepatocyte size

\begin{tabular}{lrlll}
\hline Diagnosis & $n$ & Index & $\begin{array}{l}(95 \% \text { confidence } \\
\text { limits })\end{array}$ & Analysis \\
\hline $\begin{array}{l}\text { Normal or near-normal liver } \\
\text { (non-alcoholic) }\end{array}$ & 8 & 138 & $(130-147)$ \\
$\begin{array}{l}\text { Chronic active hepatitis } \\
\text { (non-alcoholic) }\end{array}$ & 15 & 133 & $(128-139)$ \\
$\begin{array}{l}\text { Cirrhosis } \\
\text { alcoholic }\end{array}$ & 11 & 126 & $(109-138)$ \\
non-alcoholic & 5 & 124 & $(109-138)$ \\
\hline
\end{tabular}

*The index reflects the sum of the total number of cross sections with the Zeiss graticule (see text).

TABLE III Correlations ( $r$ ) between changes of aggregated features in periportal, lobular and [periportal+lobular changes] and the wedged hepatic venous pressure gradient $(W H V P G=W H V P-F H V P)$ in different groups of patients

\begin{tabular}{|c|c|c|c|}
\hline Patients ( $n$ ) & $\begin{array}{l}37 \\
\text { Four } \\
\text { categories }\end{array}$ & $\begin{array}{l}29 \\
\text { (cirrhotics } \\
\text { excluded) }\end{array}$ & $\begin{array}{l}29 \\
\text { (controls } \\
\text { excluded) }\end{array}$ \\
\hline \multirow[t]{2}{*}{$\begin{array}{l}\text { Histology } \\
\text { Periportal changes } \\
\text { Lobular changes } \\
\text { Periportal + lobular changes }\end{array}$} & $\begin{array}{l}0.590 \dagger \\
0.635 \dagger \\
0.660 \dagger\end{array}$ & $\begin{array}{l}0.498 \dagger \\
0.528 \dagger \\
0.546 \dagger\end{array}$ & $\begin{array}{l}0 \cdot 287 \text { (ns) } \\
0.416^{\star} \\
0.407^{\star}\end{array}$ \\
\hline & \multicolumn{3}{|c|}{ Wedged hepatic venous pressure gradient (WHVP-FHVP) } \\
\hline
\end{tabular}

${ }^{\star} \mathrm{p}<0.05 ; \mathrm{p}<<0.01$, Spearman's rank test.

changes together, and the relationship of this sum to the pressure in the portal vein (WHVPG) The miscellaneous group has been included in these calculations.

Correlations were also calculated between the scores of the periportal and lobular areas. The results were $r=0.756 \quad(p<0.001)$ for [near-normals $+\mathrm{CAH}+\mathrm{CAHTC}$ ] and $\mathrm{r}=0.558$ $(p<0.001)$ for [CAH +CAHTC + Cirrhosis] .

\section{QUANTITATIVE LIGHT MICROSCOPICAL} ASSESSMENT

The results of calculated hepatocyte size indices in 34 patients are summarised in Table II. The indices are inversely related to the cell size, that is, the higher the index, the smaller the cells. The indices of the patients with near normal liver differed from patients with non-alcoholic chronic active hepatitis but the differences were not significant. Significant differences were found between patients with near normal liver and cirrhosis however (both of alcoholic and non-alcoholic origin). Eleven abusers of alcohol had a lower hepatocyte size index (125 (9.8)) than 22 non-cirrhotic non-alcoholic patients (135 $(10.0)) ; \mathrm{p}<0.001)$. This difference was not related to the diagnostic histological categories (fatty change, hepatitis' cirrhosis) or to any other specific changes seen on liver biopsy.

The wedged hepatic venous pressure gradient (WHVPG) had an inverse relation to the indices $(r=-0.350, p<0.05)$. In many biopsies of cirrhotic patients, the counts were rather constant at a low level (approximately 120-130), whereas in the patients with near-normal liver they were remarkably constant at a higher level. Occasionally, however, in cirrhotic patients very high scores were obtained (approximately 150-160).

\section{VOLUME DENSITIES BY ELECTRON}

\section{MICROSCOPY}

The results of the assessment of volume densities of hepatocytes (Vh), sinusoidal space (Vs), Disse's space (Vds) and Disse's space collagen (Vdsc) are summarised in Table IV. No significant changes for $\mathrm{Vh}$ and Vs were found between the various categories. Vds and Vdsc in near-normal livers were significantly less than in other groups $(\mathrm{p}<0.01)$. Vds and Vdsc were significantly increased in the group of chronic active hepatitis patients compared with near normal subjects ( $p$ values $<0.01$ and $<0.003$ respectively)

\section{Discussion}

In the early 1950 s newer techniques showed that portal hypertension could precede the onset of cirrhosis. $^{8-9}$ One possible reason was the presence of intrahepatic arterioportal venous anastomoses. These had been proposed in the 19th century by von Frerichs $(1861)^{17}$ and such shunts were shown by Herrick $(1907)^{18}$ and confirmed by Dock (1942)..$^{19}$ Popper et al $(1952)^{20}$ believed that arteriovenous channels might transfer high hepatic arterial pressure to the low portal pressure bed.

Current theories and research in this field are based on three aspects, namely passive resistance to flow (backward flow theory ${ }^{21}$ ), hyperdynamic portal circulation (forward flow theory ${ }^{22}$ ) and possibly humoral factors, which might actively increase of lower resistance to flow. Shaldon $(1962)^{24}$ belongs to the first who worked along the hormonal lines finding increased concentrations of blood catecholamines in cirrhotic patients; he thought this to be responsible for increased resistance to flow. Contractile cells (myofibroblasts) respond to humoral factors with an increase in active resistance..$^{2-3}$

The present study was directed towards the possible role of anatomical changes in the liver which might provide passive resistance to flow. With progression of disease from chronic active hepatitis towards cirrhosis we found a significant increase in wedged hepatic venous pressure gradients. The correlations between pressures and morphological changes were maintained in all patients except those with cirrhosis and miscellaneous conditions. It must be assumed

TABLE IV Quantitative assessment (volume densities (SD)) at electron microscopy of the liver biopsies of 34 patients, subdivided according to diagnostic light microscopical categories. (For statistical significance of the findings see text)

\begin{tabular}{|c|c|c|c|c|c|}
\hline \multirow[b]{2}{*}{ Diagnostic category on light microscopy } & \multirow[b]{2}{*}{$n$} & \multicolumn{4}{|c|}{ Volume densities } \\
\hline & & $V h$ & Vs & $V d s$ & $V d s c$ \\
\hline $\begin{array}{l}\text { Normal or near normal liver (alcoholic) } \\
\text { Chronic active hepatitis (CAH) (non-alcoholic) } \\
\text { CAH in transition to cirrhosis (alcoholic) } \\
\text { Cirrhosis (alcoholic) }\end{array}$ & $\begin{array}{r}10 \\
10 \\
9 \\
5\end{array}$ & $\begin{array}{l}0.79(0.56) \\
0.78(0.04) \\
0 \cdot 80(0.06) \\
0.76(0.08)\end{array}$ & $\begin{array}{l}0 \cdot 15(0 \cdot 04) \\
0 \cdot 13(0 \cdot 03) \\
0 \cdot 13(0 \cdot 04) \\
0 \cdot 13(0 \cdot 03)\end{array}$ & $\begin{array}{l}0.06(0.01) \\
0.08(0.02) \\
0.08(0.05) \\
0.09(0.02)\end{array}$ & $\begin{array}{l}0.02(0.01) \\
0.03(0.01) \\
0.02(0.01) \\
0.03(0.15)\end{array}$ \\
\hline
\end{tabular}


that other factors such as revascularisation were involved.

It should be noted that increase in lobular changes accompanies progression in periportal changes. This hinders the analysis of the contribution of the separate changes seen by light microscopy to the increase in pressure gradients, because the proportional contribution of each of these factors cannot be assessed. Our findings help to explain the observation that, particularly in chronic active hepatitis, the WHVPG underestimates the portal venous pressure. ${ }^{25}$ A possible explanation is, that the pressure gradient drops initially because of resistance caused by periportal changes, whereas a further drop is secondary to sinusoidal and lobular components.

Hepatocyte size tends to increase with progression of hepatic disease, whatever the cause. This finding is in agreement with others. ${ }^{+726}$ Assessment of hepatocyte size is considered to be mandatory in any case of portal hypertension without obvious cause because hepatocyte enlargement might be the single pathological mechanism for portal hypertension. ${ }^{6}$ In a perfused liver model, osmotically induced hepatocyte enlargement was shown to induce portal hypertension. ${ }^{7}$ None of our patients, however, had an increased portal pressure without definite further changes on liver biopsy. Whether there is a 'critical value' above which the portal venous pressure rises more in relation to hepatocyte size has not been assessed in this study.

The volume density of the hepatocytes did not differ significantly between the four diagnostic groups. There were, however, problems of sampling. It was easy to select midzonal areas in patients with near normal livers or chronic active hepatitis, but problems arose with progression of changes towards cirrhosis. Certain random pictures were disregarded because they showed only collagen. Thus, although differences between near normal liver and chronic active hepatitis reflect 'true' differences, the differences between the other groups may in part reflect selection. The volume density of the hepatocyte mass $(\mathrm{Vh})$ in the specimens used for electron microscopical analysis were similar, so that the changes in collagen relate roughly to the same amount of hepatocyte volume in areas where hepatocytes are present. In these areas the increase of collagen in Disse's space is a feature of alcoholic and non-alcoholic liver disease. The relevance of this observation for the development of portal hypertension is, however, hard to assess. In our specimens of non-alcoholic patients we could not show a significant decrease in size of sinusoidal space with progression of the anatomical changes. This finding is in agreement with others who found in contrast that alcoholics showed sinusoidal compression. ${ }^{27}$ Even if the size is not decreased, increased rigidity of the wall of the sinusoids might add to the increased resistance to flow. The resistance to flow is an inverse function of the fourth power of the radius and minor changes in the radius of the vessel might be responsible for major changes in the resistance to flow.

Our study does not provide evidence for or against the hypothesis that the increased sinusoidal pressure might itself induce fibrogenesis. ${ }^{5}$ However, many other mechanisms have been proposed to explain collagenisation.

The present study concentrated on a few of the many anatomical changes which may contribute to the passive resistance to portal venous flow. The level of assumed obstruction was a basis for the clinical classification of portal hypertension. Although this classification is helpful as a clinical guide, it should be realised that this will only partly correspond with reality because of the likely mixed origin of the level of obstruction and to the variety of other factors which determine portal venous pressure. Although in the early stages of disease some relationship between morphological changes and increase in portal venous pressure could be observed, a more definite model of portal hypertension should probably take both passive and active contributions to resistance to flow into account. It could be that in such a model our findings in early disease would remain relevant but that in endstage disease metabolic and humoral factors might become increasingly important.

Miss $\mathrm{J}$ Lewin and Mrs $\mathrm{L}$ Boxer provided invaluable help in processing specimens for electron microscopy. We are grateful to the staff of the Histopathology Laboratory for special stains. Mrs C Wood kindly advised on statistics and Mrs Nouri (Departmen of Nephrology) advised on morphometry. Dr R Dick and his staff Department of Radiology) helped with the pressure studies. DJvL received support from the Netherlands Organisation for the Advancement of Pure Research (ZWO).

1 Kelty RH, Baggenstoss H, Butt HR. The relation of regenerated liver nodule to the vascular bed in cirrhosis. Gastroenterology 1950; 15: 285-95.

2 Bhathal PS. Presence of modified fibroblasts in cirrhotic liver in man. Hum Pathol 1972; 4: 139.

3 Bhathal PS, Grossman HJ. Reduction of the increased portal vascular resistance of the isolated perfused cirrhotic rat by vasodilators. F Hepatol 1985; 1: 325-37.

4 Orrego H, Medline A, Blendis LM, et al. Collagenisation of Disse space in alcoholic liver disease. Gut 1979; 20: 673-9.

5 Orrego H, Blendis LM, Crossley IR, et al. Correlation of intrahepatic pressure with collagen in the Disse space and hepatomegaly in humans and in the rat. Gastroenterology $1981 ; 80: 546-56$

6 Blendis LM, Orrego H, Crossley IR, et al. The role of hepatocyte enlargement in hepatic pressure in cirrhotic and noncirrhotic alcoholic liver disease. Hepatology 1982; 5: $539-46$.

7 Colman JC, Britton RS, Orrego $\mathrm{H}$, et al. Relation between osmotically induced hepatocyte enlargement and portal hypertension. Am f Physiol 1983; 245: 382-7.

8 Paton A, Reynolds TB, Sherlock S. Assessment of portal hypertension by catheterisation of the hepatic veln. Lancet hypertension by

9 Reichman S, Davis WD. The splenic approach to the portal circulation. Intrasplenic and intrahepatic tissue pressure measurement in acute and convalescent hepatitis. $A m \mathcal{F} M e d$ 1957; 33: 609-15.

10 Boyer T, Triger DR, Horisawa, $M$, et al. Direct transhepatic measurement of portal venous pressure using a thin needle. Gastroenterology 1977; 72: 584-9.

11 Moehrl M, Wannagat L, Gehring D. Portal hypertension in chronic hepatitis. Comparative manometric and clinicochemical examination. Klin Wochensch 1980; 58: 207-8.

12 Groszmann RJ, Glickman M, Blei A. Wedged and free hepatic venous pressure measured with a balloon catheter. Gastroenterology 1979; 76: 254-8.

13 van Leeuwen DJ, Sherlock S, Scheuer PJ, Dick R. Wedged hepatic venous pressure recording and venography for the hepatic venous pressure recording and venography for the assessment of pre-cirrhotic and cirr.

14 Sherlock S. Classification and functional aspects of portal Sherlock S. Classification and functional
hypertension. Am $\mathcal{J}$ Surg 1974; 127: 121 .

15 Conn HO, Groszmann RJ. The pathophysiology of portal hypertension. In: Arias IM, Popper H, Schachter D Shafritz DA, eds. The liver: biology and pathobiology. New York: Raven Press, 1982; 821-48.

16 Weibel ER. Stereological methods. London: Academic Press, 1979-80.

17 Frerichs FT. A clinical treatise on disease of the liver. The New Sydenham Society 1861; 2: 28-30, quoted by Hales et al Am F Pathol 1959; 35: 909.

18 Herrick FC. An experimental study into the cause of in creased portal pressure in portal cirrhosis. $\mathcal{F}$ Exp Med 1907 9: 93-100.

19 Dock W. The role of increased hepatic arterial flow in porta 
hypertension of cirrhosis. Trans Assoc Am Physicians 1942; 57: 302-6.

20 Popper $\mathrm{H}$, Elias $\mathrm{H}$, Petty DE. Vascular pattern of the cirrhotic. Am f Clin Pathol 1952; 22: 717 .

21 Moreno AH, Burchell AR, Rousselet LM, et al Portal blood flow in , Burchell AR, Rousselet LM, et al. Portal blood 22 Witte CL, Witte MH, Bair G, et al. Experimental study of hyperdynamic vs stagnant mesenteric blood flow in portal hypertension. Ann Surg 1974; 179: 304-10.

23 Vorobioff J, Bredtfeldt JE, Groszmann RJ. Hyperdynamic circulation in portal hypertensive rat model - A primary maintenance of chronic portal hypertension. Am $\mathcal{f}$ Physiol $1983 ; 244: 652-7$
24 Shaldon C. Dynamic aspects of portal hypertension. Ann $R$ Coll Surg Engl 1962; 31: 308 .

25 Miyakawa H, Iida S, Leo MA, Greenstein RJ, Zimmon DS Lieber CS. Pathogenesis of precirrhotic portal hypertension in alcohol-fed baboons. Gastroenterology 1985; 88: 143-50. 26 Poynard T, Degott C, Munoz C, Lebrec D. Relationship between degree of portal hypertension and liver histologic lesions in patients with alcoholic cirrhosis. Dig Dis Sci 1987; 32: $337-43$.

27 Vidins EI, Britton RS, Medline A, Blendis LM, Israel Y, Orrego $\mathrm{H}$. Sinusoidal caliber in alcoholic and non-alcoholic liver disease: diagnostic and pathogenetic implications. Hepatology 1985; 5: 408-14. 